\title{
Sparking social initiation behaviors in children with Autism through Full-body Interaction
}

\author{
Joan Mora-Guiard ${ }^{\mathrm{a}, 1}$, Ciera Crowell ${ }^{\mathrm{a}}$, Narcis Pares $^{\mathrm{a}}$, Pamela Heaton ${ }^{\mathrm{b}}$ \\ ${ }^{a}$ Universitat Pompeu Fabra, Carrer Roc Boronat, 138, 08018 Barcelona, Spain \\ ${ }^{b}$ Goldsmiths University of London, New Cross, London SE14 $6 \mathrm{NW}$, UK
}

\begin{abstract}
We present the full-body interaction system Lands of Fog, a multi-user experience designed with and for children with ASD to foster social initiation and collaborative behaviors. Autism Spectrum Disorder (ASD) is a neurodevelopmental disorder which negatively impacts social communication abilities, resulting in significant problems forming and maintaining relationships with peers. Research suggests the use of Information and Communication Technologies to offer structured activities where individuals with ASD will be motivated to practice and develop these social behaviors, activities which deployed in inclusive schools could also help for social inclusion. We have completed two studies where children with ASD played with neurotypical children, one in a laboratory controlled setting and one in an inclusive elementary school. Results indicate that the system was successful in fostering motivation, socialization and collaboration. Moreover, the system was positively perceived by children and school professionals.
\end{abstract}

Keywords: Autism Spectrum Disorder, ASD, Full-body interaction, Information and Communication Technologies

\footnotetext{
${ }^{1}$ Corresponding author. E-mail: joan.mora@upf.edu
} 


\section{Introduction}

\subsection{Autism}

Autism Spectrum Disorder (ASD) is a neurodevelopmental disorder characterized by behavioral abnormalities in the domain of social communication, and also by restricted and repetitive behaviors, interests and activities [1]. Current ASD diagnosis is based on different sources such as standard assessments, observing the individual in different structured scenarios, or the knowledge of therapists and caregivers who treat the individual [2].

Diagnostic tools have been developed for assessing whether a subject is within the Autism Spectrum and the severity level of the symptoms. One such diagnostic tool is the Autism Diagnostic Observation Schedule (ADOS) [3. ADOS consists of a set of structured and semi- structured scenarios that psychologists conduct with individuals, for a posterior evaluation that leads to a final quantitative score which defines the severity of the disorder (where 4 is the cutoff value for an ASD diagnosis in scale from 1 to 10). ADOS is divided into 4 modules, taking into account age and verbal capacity of the individual. The results from these assessment tools can be used as inclusion criteria for research to target a specific sub-group.

Research and therapies tend to focus on specific sub-groups, such as high or low functioning level, for better adapting their work to characteristics specific to a range of the spectrum. The following research focuses on children in the sub-group of the spectrum called High-functioning ASD (HFASD). HFASD is defined by having a diagnosis of ASD and an IQ higher than 70 [4, and this subgroup of people are believed to have higher chances of leading an autonomous life if properly assisted in youth.

\subsection{Integration difficulties}

For individuals with ASD forming and maintaining relationships with peers may be challenging and problematic due to deficits in social communication skills. This population has difficulties interpreting non-verbal social cues, which 
commonly leads to misunderstanding the intentions of others [5]. Moreover, individuals with ASD have problems engaging socially as they often do not properly understand the way they are being perceived by other interlocutors [6.

Difficulties forming and maintaining relationships with peers may lead to an increase in social fragmentation in school contexts for children with ASD [7]. Furthermore, difficulties in social relationships can affect individuals learning abilities 8 . Thus, it might be necessary to provide support during unstructured social scenarios to counter social fragmentation [7. A recent study in schoolbased intervention programs designed to improve social experiences, presents findings that youth with ASD prefer activity-based learning with peers rather than direct instruction activities [9].

\subsection{Autism and ICT}

Brown and Murray, while researching how to engage children with ASD, found that this population has an affinity towards information and communication technologies (ICT) thanks to their linearity and discreteness [10]. As a result, over the last two decades there has been an increasing interest towards research focused on the use of ICT therapies for people with ASD. In addition to being well received by children with ASD, computer-based technologies are ideal to present scenarios which can give immediate and consistent feedback to children with ASD [11 and where change can be introduced and regulated gently [12, offering pleasant scenarios for children with ASD for learning or therapy.

Existing research recognizes the effectiveness of technology for the acquisition of new skills by children with ASD. In the field of Video Modeling (i.e. the teaching process of video recording and displaying content as a visual support for the target skill or behavior) research has shown the benefits of using ICT for achieving task completion abilities [13, 14]. Desktop multimedia has also been used to support teaching for the recognition of complex emotions in face and voice (i.e. Mind Reading abilities) [15] or even maintaining appropriate spatial 
boundaries in social interaction [16].

\subsection{Full-body interaction and Autism}

In this article we present the Lands of Fog system, the outcome of the research project IN-AUTIS-TIC, Integration of Children with Autism into Society using ICT.

Our approach to the use of ICT for developing intervention for children with ASD came from a specific area in Human Computer Interaction (HCI): FullBody Interaction, which can be understood as the use of motion and activity in a physical space by the user's body as an interaction mediator. The research project focused on the design of a playful full-body interaction environment specifically designed for children with ASD to play with a typically developed child. Designing an environment which children approach in a playful way was based on studies which show that behavioral therapy for ASD is effective for learning when using play based approaches [17, 18, 19].

The potential of full-body interaction systems is based on cognitive theories that stress the relationship between physical activity and cognitive processes, known as Embodied Cognition. Embodied cognition theories emphasize the role of the body and sensorimotor activity when interacting with the physical environment in the development of cognitive processes [20. Embodied cognition provides a theoretical base for defining the potentials of intervention through full-body interaction systems. Research shows that an increase in body movements in multiplayer settings increases the social nature of the gaming experience 21], thus making full-body interaction systems an interesting approach for social therapy and intervention.

The overarching objective of the full-body interaction system was to motivate children with ASD to engage with the system, to help them learn and practice basic social interaction and understand the benefits of collaborating with peers while playing and exploring. 


\section{Background}

\subsection{Virtual Environments and Autism}

Research with Virtual Environments (VE) has focused on opportunities for mediating collaborative environments [22]. In 2010, Cheng and Ye 23] explored the potentialities of a collaborative virtual learning environment for developing social competence in children with ASD. Results showed that this kind of technologies can have positive impact in social interaction learning.

Virtual Environments have been also successfully used for teaching social skills to children with ASD [24. In 2007 Mitchell et al. assessed the use of VEs for helping young people with ASD to learn social understanding with positive results [25]. In the experiment, they observed an improvement on social skills during the sessions, not only confined to the particular virtual context of the application but also generalized to everyday life.

\subsection{Full-Body Interaction and Autism}

One of the first approaches on full-body interaction for ASD children was the MEDIATE project, a multi-modal adaptive environment for children with severe autism. The scope of the project was to provide a sense of control through interaction, thus providing a sense of agency [26]. MEDIATE was designed "for children with autism to have fun and have the chance to play, explore, and be creative in a controllable and safe space" [26]. The installation was capable of adapting itself to enhance user's interaction.

Another full-body interaction system was The Pictogram Room. The project scope was to teach children with ASD to understand the relation of pictograms with body posture 27. The Pictogram Room was also aimed at giving support for imitation therapy for social behavior learning.

The Echoes Project was a full-body interaction system designed for intervention in children with ASD 28. The scope of the project was to develop a virtual environment to facilitate exploration and acquisition of social interaction skills in children with ASD from 5 to 7 years old. The system was based on 
an avatar which could interact with the users for practicing and learning joint attention abilities.

\subsection{Participatory Design}

When designing systems and artifacts for people with special needs, it is not only important to include them in the design process to better grasp their necessities, but also to better understand the potential of the solution being developed 29].

For the design of the Lands of Fog interactive system we adopted a Participatory Design (PD) [30] approach. Five PD sessions were conducted with 4 male children with HFASD. As Autism is more prevalent in males than females in a ratio of 5 to 1 , it was agreed with the lead psychologist that we would work with male children with ASD in the project. Different approaches were adopted for helping children express their insights and provide content for the final design. The five PD sessions were designed in an incremental fashion. During the first two sessions children had the opportunity to define the aesthetics of the virtual environment of the installation. Each child designed their own environment, and all the ideas were subsequently discussed and integrated into

a final environment design. In the following two sessions children were able to propose elements and creatures that would inhabit the world they designed and how these would behave and interact. Finally, in the last session the 4 children with ASD had the chance to embody the potential gameplay of the full-body interaction system in a Wizard-of-Oz activity. This consisted of a system that projected on the floor the designs of the children drawn on paper to allow them to experience their designs at full-body scale. For an in-depth explanation of the PD process conducted for the design of this project refer to [31].

\section{The system}

Lands of Fog is a full-body interaction system designed for children with ASD to play with a typically developed peer in which both users actively explore 


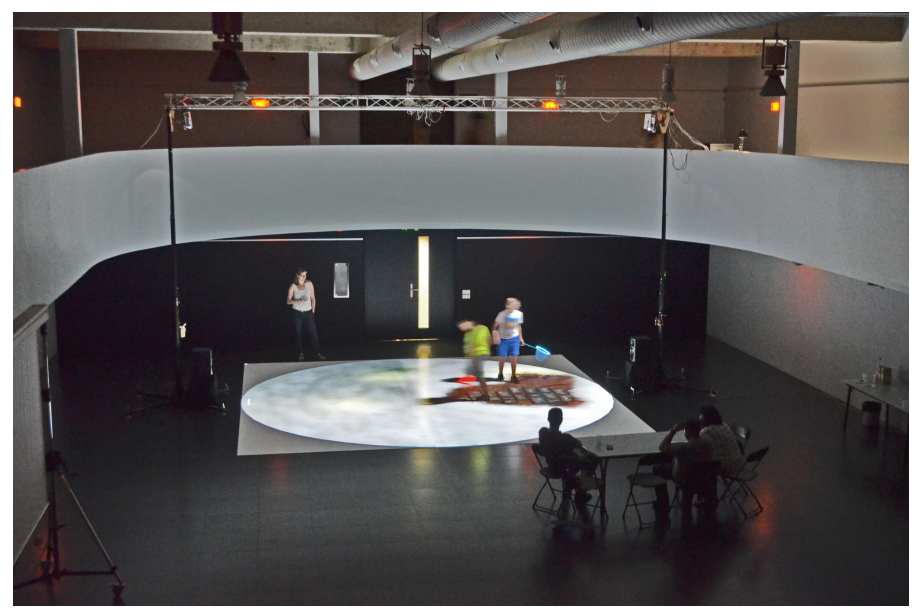

Figure 1: The Lands of Fog installation. Two children are playing in the virtual environment, while a psychologist (in the background) oversees the session. Parents are seated at a table in the foreground.

and collaborate to discover a myriad of interactive virtual elements. The game was designed to motivate engagement, while scaffolding social and collaborative behaviors between users by tracking their activity and adapting to it.

We now briefly describe the physical set-up and the game mechanics. For a thorough description of the design process and the supporting criteria refer to Mora-Guiard et al. 32.

The full-body interaction installation is based on a large floor projection of 6 meters in diameter, projected by two Full HD projectors (figure 1). The system presents a virtual environment where users explore a magical world covered by a dense layer of fog. The shape of the projection is circular, designed to maintain user engagement with the system and prevent users from adopting passive behaviors. The circular design prevents potential isolation of children in corners. Moreover, it tends to guide the participants back towards the middle of the physical and virtual environment. This is based on the Lightpools fullbody interaction experience, which also used this configuration for fostering exploration and achieving serendipitous encounters [33]. 


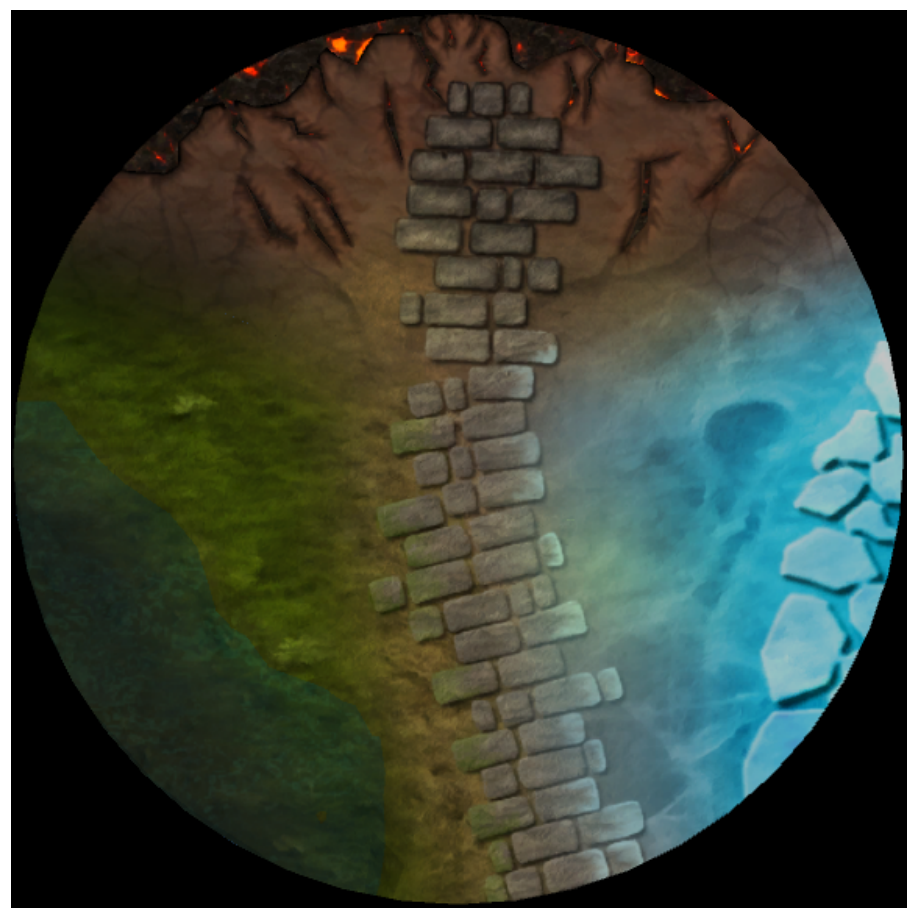

Figure 2: Overview of the environment. Top: the lava zone; left: the grass and pond; right: the ice zone; central axis: the cobblestone path.

\subsection{The virtual environment}

The virtual world was designed during the aforementioned PD sessions. The outcome of the design process was a world where three different regions meet: a grass zone with a pond, a deserted zone with little pools of lava and a frozen tundra zone. A cobblestone path crosses through this world (figure 2). The different zones were proposed by the children during the PD sessions and adapted to offer a rich world in the 6 meter wide circular playground. Efforts were made to create an environment which matched the world described by the children in the PD sessions. Including content generated by individuals of the target population is a way of creating an environment that will be pleasant and interesting for that specific group of users [29].

The world is covered by a dense layer of virtual fog, which the users can partially open to reveal part of the world which lies below as they wander 


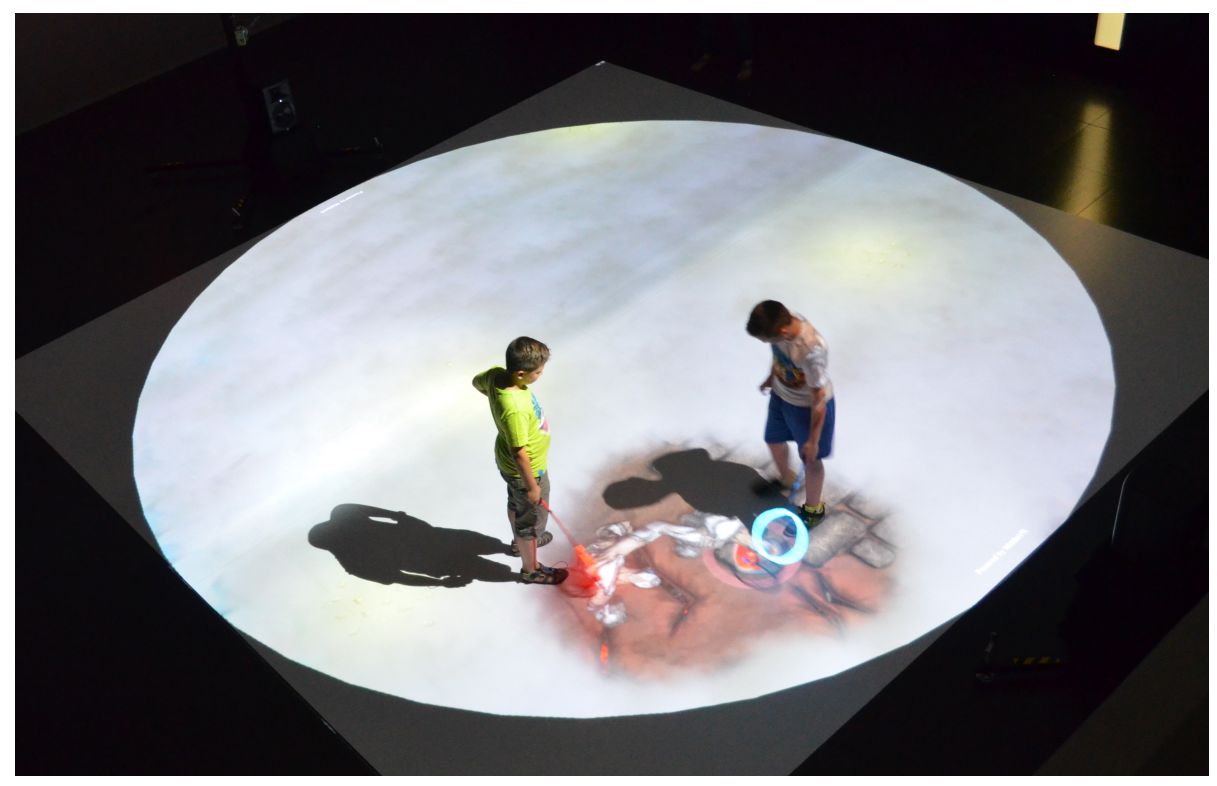

Figure 3: View of the virtual environment covered by virtual fog. The fog opens to reveal the underlying world only where each user locates their handheld device (butterfly net).

through the installation (figure 3). The objective of having such a rich virtual environment covered by fog was twofold. First, to motivate users to adopt an active attitude towards the game, the world would only be revealed as users explored. The strategy of limiting what the user can view is referred to as a "peephole", a design strategy which Dalsgaard and Dindler proved to be a good approach to promote exploration [34. Second, limiting what users can see was thought to be beneficial for children with ASD, who can be easily overwhelmed when presented with numerous stimuli. Limiting the viewing content was meant to help them focus while exploring the environment, as only one part of the virtual environment could be seen at a time.

For interacting with the virtual environment, users carry a glowing butterfly net, which simultaneously functions as: a cognitive offloader to channel the users attention into the play setting; an object that allows the children to impact the virtual world from the physical world; and an aid for the custom developed tracking system. The environment is populated by swarms of fireflies which can be virtually caught with the butterfly net, utilizing the familiar dynamic of 
catching insects in a natural manner. Once caught, fireflies change their color to match the one of the user's net who caught them. To discourage competitive behaviors, children can only catch the fireflies which have not yet been caught and have hence not changed color. This prevents users from stealing fireflies which belong to the other user.

\subsection{Virtual partners}

As users hunt a sufficient amount of fireflies, these transform into a magical creature which follows the user thereafter (figure 4). In Lands of Fog there are a total of 14 creatures that users can discover while playing. All the creatures were conceived by the PD participants. Once they appear for the first time, the creatures open a new level of interaction richness with the system. This interactive progression was designed to offer the users an initial simple-to-grasp mechanic that would foster their motivation to explore while at the same time getting acquainted with the system and the environment. Davis et al. suggested that, when designing interactive systems for individuals with ASD, it was a good practice to first design features which would be readily accepted and understood by users, while novel and richer elements can be gradually introduced later on 35 .

Once a user has a creature, they can share it with their peer by moving within close proximity, constituting an easy interaction which simplifies the understanding that things can be shared in the world. If users adopt a passive attitude while playing, creatures will try to catch their owner's attention using interesting animations such as greeting their owner. All these creature behaviors were designed to motivate users to remain engaged. Eventually, if users do nothing for a long time, their creatures will even try to move closer to the other user. This behavior is one of the initial mechanics devised for trying to spark socialization behaviors between users during gameplay.

When users' creatures come close to each other, they perform a greeting action towards the other. Therefore, creatures are models of social behaviors for the players, and also try to help children understand that there might be 


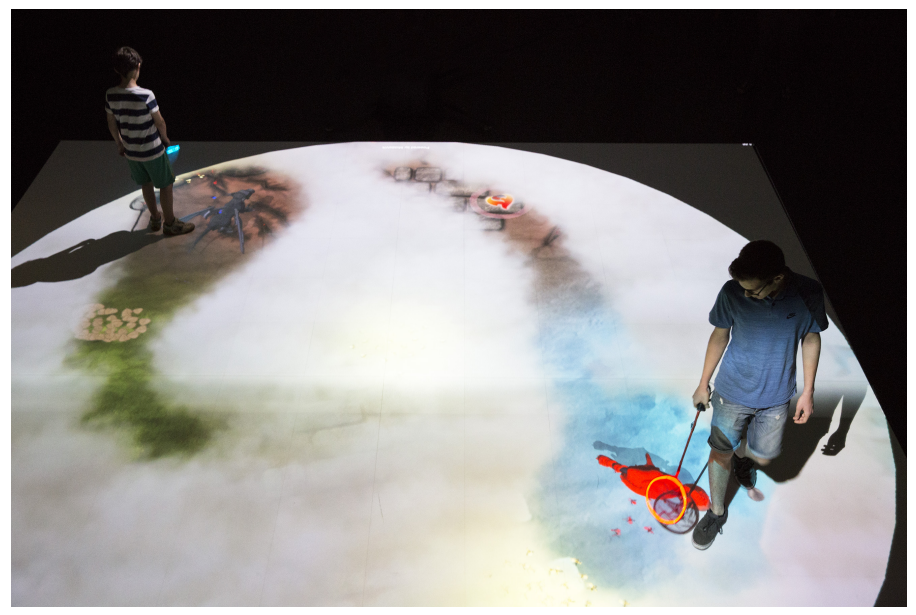

Figure 4: Two players are exploring the world with their creatures. The child in the background has Quadruped Dragon as a companion, while the one in the foreground has the Crab Man.

potential interactions between virtual elements. If the two users get even closer, the creatures will perform a choreographed encounter to merge and create new creatures, which take the place of the old ones. This way, children can understand that if they want to discover all the creatures that inhabit the virtual world, they will have to collaborate. Nonetheless, if users keep hunting fireflies without merging their creatures, they will transform the creature by changing its external appearance. Each creature has up to 4 variations, making a total of 56 unique creature alternatives.

\subsection{Interactive virtual elements}

The scenario, or world in which the users play, is not just inhabited by a number of interesting creatures but is also populated by virtual elements which the users can discover while exploring. These game elements spark the interest of users, who share their discoveries with their partner and proceed to explore the world together. If a user approaches the virtual elements, their creature will point towards the element and make an exclamatory remark. This way the creature tries to communicate to the child that the element might be a point of interest. Again, these behaviors were devised to encourage the 
user to explore, and also to promote an inquisitive attitude that would foster socialization between users.

The virtual elements can only be activated when both users bring their creatures close to the element at the same time. When both creatures converge by the object, they will manipulate the virtual element, which will respond with a unique playful animation and then disappear, while the creatures celebrate their discovery. After a while, a new interactive element will appear where the previous virtual element was waiting. This way, only through collaboration users are able to discover all the different interactive virtual elements that populate the magic world.

\section{Research methodology}

\subsection{Two studies}

Over the course of three months, the system was tested with a total of 34 children with ASD in two different European countries. Pilot trials took place in our university in Barcelona, followed by two months of testing in the same location with children with ASD from the area. Next, the system was installed in The Elmgreen School, an inclusive elementary school in London, where schoolchildren from the Special Educational Needs program participated in experimental sessions through the course of one week. It was seen that, despite the difference in educational and cultural settings, the system was successful in fostering social behaviors in both contexts, and was received positively by children, parents and school personnel. The following section will describe the two experimental procedures where the full-body interactive environment fostered positive social behaviors in children with ASD. We provide full results and a discussion on these in the sections that follow.

\subsection{Ethical validation}

The research methodology and protocol was validated by the ethical committee from Universitat Pompeu Fabra in Barcelona, which also validated Barcelona 
experimental trials. Goldsmiths ethical committee validated the London experiments undertaken at the The Elmgreen School. Parents and caregivers of the children who participated in the experiments were informed through meetings with researchers. Parents were asked to sign informed consents to certify they had been adequately informed and that they agreed with their children participation. Consents informed that the collected data would be anonymous and that participants had the freedom to leave the experiments whenever they wanted. Finally, informed consents also asked for permission regarding dissemination of the results and visual media. Parents of the participants in the PD sessions were also properly informed and were also asked to sign informed consents for their children participation. Children were informed of the activities they were going to undertake and were free to leave whenever they wished, including when they were tired, bored or uninterested by the activity.

\subsection{Barcelona}

\subsubsection{Methods}

The system was tested with children with ASD recruited by a psychologist from autism centers in Barcelona and the surrounding areas. All of the sessions took place in a large multi-use space at Universitat Pompeu Fabra, Barcelona, where the system was set up. These experimental sessions were preceded by one week of pilot trials, which helped to calibrate the system for young users and finalize the experimental procedure. Pilot trial sessions were followed by an interview with the children who participated to gather feedback on gameplay and design. The children who participated in the pilot trials did not participate in the proceeding experiments. After the pilot trials, changes were made in the system, including creating a greater sense of anticipation leading up to game

events. This was accomplished with additional multisensory elements such as visual and auditory clues, so that children could learn and perform game actions with greater fluency.

Experimental sessions were planned so that children with ASD attended 3 separate sessions, each with a different TD playing partner. Sessions were 
planned with 5-7 days between sessions, which allowed us to observe changes in social behaviors and willingness to collaborate over time. Data was collected through video coding recorded sessions, analysis of system data, and reviewing parents' questionnaires. The video coding scheme used for Barcelona and London experiments was developed in unison with psychologists from Hospital Sant Joan de Déu and the lead psychologist of the research project. The coding scheme was developed for observing social initiations, requests, responses, shared behaviors and gestures. Each participant's playing data was recorded in log files during sessions through the use of a player tracking system. This data included information such as child position and game events. Finally, questionnaires were specifically developed for Barcelona experiments. The questionnaires were administered to parents the first day and at the end of each session. Parents were asked to evaluate their childs attitude and behavior during each play session as compared to their habitual status.

\subsubsection{Participants}

Sixteen male children with HFASD between the ages of 10 to 14 were recruited for this study. The inclusion of only male participants was decided with the project's psychologists, given that Autism is more prevalent in the male population. A total of six children did not complete the required number of sessions (but four of them did at least one or more sessions), resulting in a final sample size of 10 male children with ASD $(\mathrm{N}=10)$. The diagnosis of Autism was determined by the Autism Diagnostic Observation Schedule (ADOS) module 3, which is designed for young people with verbal fluency, with a minimum diagnosed severity of 4 . It was decided that verbal fluency would be essential to achieve the level of collaboration required to play the game, so the child with ASD could play without the help of a psychologist or parent. A total of 16 typically developed male children were involved in the project as playing partners for the children with ASD. As a measure to prevent problems playing or comprehending the game, the children with ASD and the typically developed partners were screened for epilepsy and also were required to have an IQ of 
minimum 70 according to the Wechsler Intelligence Scale for Children (WISC) [36. Due to the large recruitment effort undertaken by the psychologists, the origin of children with ASD showed to belong to a wide range of neighborhoods, socioeconomic levels, and video gaming fluencies as verified during the study through simple questions in the questionnaires administered to parents.

\subsection{London}

\subsubsection{Methods}

The game was installed in the multipurpose room of an inclusive elementary school in South London, where a Special Educational Needs unit managed the integration of children with ASD into classes with typically developed children. Over the course of one week, children with ASD were invited by the school experts to participate in "a full-body game where they would hunt for mythical creatures". Sessions were planned into the school timetable, so all testing took place during school hours on the school campus. The approach of the trials in London was specifically different from the approach in Barcelona, as the children only played one session each, stayed in the familiar environment of their school, and were guided by the presence of known school personnel.

Data gathering in London followed an identical procedure to that for Barcelona, with the exception of subjective experience questionnaires which were administered directly to children instead of parents. As the children with ASD were attending an inclusive elementary school, school experts confirmed that children would have sufficient cognitive abilities to formulate appropriate responses to one of the experts acting as interviewer. These questionnaires were adapted to the unique experimental format of the inclusive school, given that the children only attended a single session.

To assist in completing the questionnaires, a special educational needs assistant from the school conducted post-session interviews with the children with ASD. The interviews were mainly structured around information related to the children's impression of the game and working with a partner. Example questions included whether the children would return to play the game and whether 
they felt inclined to get to know their partner better after playing. The assistant had a close relationship with the children, and was able to report on topics such as changes in the child's activity, behavior or flexibility level while playing the game. In addition, we decided that the assistant would be able to guide the children with expressing their opinions. Data was also gathered from typically developed children, who also responded to the same post-session questionnaire.

\subsubsection{Participants}

A total of 40 children were recruited to participate in a week-long experimental session at the integrated school in London. Of this sample, there were 20 children with ASD and 20 typically developed playing partners, who were all attending the school at the time of the trials. In contrast to Barcelona, most children who participated in the London sessions were from the same neighborhood and educational background. The children were from low to middle income families of southern London, of diverse cultural heritages. The children varied in age from 11-15 years old. As is common with ASD sampling, the majority of participants were male, with 4 female participants with ASD compared to 16 male participants with ASD. Female participants were included because there were girls with ASD in the integrated school and we did not want to exclude them. Moreover, we wanted to explore how they behaved in the system, especially when the game had been designed by boys in the PD sessions.

The integrated school systematically uses the Social Communication Questionnaire (SCQ) to diagnose the children with ASD. Therefore, we went along with this diagnosis tool in the process of recruiting children of the school for our study. These children were attending classes along with typically developed peers, while also participating in targeted educational support and therapy sessions led by the Special Educational Needs unit of the school. A Special Educational Needs teaching assistant of the school was responsible for arranging playing partners, given the criteria that the ASD and TD child pairs would be age-matched, gender-matched, and avoiding the matching of "super partners" (children who were already good friends). 


\subsection{Procedures}

The following procedures were common to both Barcelona and London trials.

Upon arrival to each session, the children were introduced to their partner for the day and had a few minutes to exchange greetings. It was assured that none of the children had a previously established friendship, so that each game provided a unique opportunity for the child with ASD to practice interaction with a new companion. To create a natural playing environment we decided not to train TD children about how to play with their partner with ASD, as we needed their reactions to be spontaneous. To account for the wide deviation in interaction patterns among children with ASD, experiments were arranged through randomly controlled trials by changing the playing partner for each session in Barcelona.

As the game was designed with an open-ended play format, there was no set end point to the game. Therefore, it was decided after previous pilot trials that the children would play for 15 minutes per session, so the children would have sufficient time to experience all aspects of the interactive setting.

Each experimental session began with an explanation of how to hold the butterfly nets so the system could correctly track the player positions. The children were given minimal directions (such as how to hold the butterfly net for a proper tracking) so that it was their challenge to work out how to play in the experience. This was seen as a way to motivate problem-solving collaborative conversation between the children. Each session concluded with the completion of interview questionnaires regarding the child's behavior and play experience.

\section{Results}

The results were evaluated based upon the system's ability to promote users' engagement and scaffold socialization and collaboration through intelligently sparking interaction in the children with ASD and the TD peers. From these goals, we formed three evaluation criteria. In addition, information was gathered 
to assess the perception of the system from the perspective of children and school professionals.

\subsection{Evaluation criteria}

The first evaluation criterion considered that the system would motivate users to play. This was assessed through children's level of participation, activity level and flexibility while playing the game. These factors were evaluated through responses to the post-session questionnaires and through system data such as distance (in centimeters) covered through the game, the amount of features of the game interacted with and time spent engaging in active game play.

The second evaluation criterion, which measured the increase in propensity of each child to engage with other people, was assessed by observing the number of social bids, requests, and responses made by the child with ASD during the course of each session. In addition, we measured the number of social acts directly related to the game events and the perception of the game as a starting point for forming social relationships.

The third evaluation criterion, that the children would show positive social interaction attitudes, was measured through collaborative actions made by the children while playing the game. As the game was aimed at fostering collaboration between the child with ASD and the typically developed child, we analyzed the number of collaborative activities and changes in the proximity between users to search for indicators of positive social interaction attitudes.

All collected data was first analyzed for its normality with a Shapiro-Wilk test. For normally distributed data ANOVAs were used for independent variables with more than two conditions, while paired t-test where used for intrasubject two condition data. For the non-normally distributed data we used the Wilcoxon tests.

Given that the ASD screening criteria was different between the two locations, we tested for a difference in behaviors between the two studies' populations. No statistically significant difference was found. 


\subsection{Child Motivation}

\subsubsection{Increase in activity}

To evaluate motivation to play, we looked at the activity level of the child during the session, which we considered to be an indicator of whether they seemed to be understanding and willing to engage in active play.

In the laboratory setting, we saw that the distance covered by each child significantly decreased through the sessions (ANOVA: $\mathrm{F}(2,9)=45.1, \mathrm{p}<.001$ ) (table 1), while the amount of hunted insects increased through sessions (ANOVA: $\mathrm{F}(2,9)=16.9, \mathrm{p}<.05)($ table 2). As this number of actions increased in correspondence with less distance covered by the children, we understood that the children were beginning to understand the game and engage in purposeful movement. In addition, the player tracking system indicated that the number of seconds remaining still significantly decreased from first to second and third sessions in the laboratory experiments (table 3). This also supports the idea that children were demonstrating a consistent willingness to participate in gameplay through the course of the sessions.

Table 1: Distance Covered during Sessions

\begin{tabular}{cccc}
\hline Source & $\mathrm{N}$ & $\mathrm{M}$ & $\mathrm{SD}$ \\
\hline Session 1 & 10 & $35,149.3$ & $1,529.6$ \\
Session 2 & 10 & $28,947.6$ & 808.0 \\
Session 3 & 10 & $20,159.1$ & $1,353.2$ \\
\hline
\end{tabular}

Table 2: Number of Hunted Fireflies

\begin{tabular}{cccc}
\hline Source & $\mathrm{N}$ & $\mathrm{M}$ & $\mathrm{SD}$ \\
\hline Session 1 & 10 & 25.2 & 3.1 \\
Session 2 & 10 & 54.5 & 9.7 \\
Session 3 & 10 & 78.3 & 9.2 \\
\hline
\end{tabular}

Through post-session questionnaires, parents in the laboratory setting evaluated that the activity level of their children significantly increased through the sessions (ANOVA: $\mathrm{F}(2,9)=9.559, \mathrm{p}<.05)$ (table 4). The special needs assistant 
Table 3: Number of Seconds Still

\begin{tabular}{ccc}
\hline Source & $\mathrm{Z}$ & Sig. \\
\hline Session 1-1 & -2.191 & .029 \\
Session 1-3 & -2.293 & .022 \\
Session 2-3 & -.359 & .720 \\
\hline
\end{tabular}

in the elementary school concurred with this perspective, noting that 65 per cent of the children showed an increase in their activity level compared to everyday life. This marked increase in activity supports that the virtual environment was a good motivator for children to explore and play.

Table 4: Activity Level

\begin{tabular}{cccc}
\hline Source & $\mathrm{N}$ & $\mathrm{M}$ & $\mathrm{SD}$ \\
\hline Session 1 & 10 & 4.1 & 3.14 \\
Session 2 & 10 & 5.1 & 3.48 \\
Session 3 & 10 & 4.8 & 3.59 \\
\hline
\end{tabular}

\subsubsection{Increase in flexibility}

In addition to an increase in activity, in the laboratory tests parents evaluated that the flexibility levels of their children increased through sessions (table 5), and the special needs assistant at the school agreed that 70 per cent of the children with ASD showed more flexibility while playing the game than they typically did in other settings such as a school playground, drama class or mathematics class. As individuals with ASD have a tendency to maintain rigid patterns of behavior, this change in flexibility demonstrates a willingness to embrace the games ideals of exploring, sharing and adopting collaborative behaviors.

Table 5: Flexibility Level

\begin{tabular}{ccc}
\hline Source & $\mathrm{Z}$ & Sig. \\
\hline Session 1-1 & -2.414 & .016 \\
Session 1-3 & -2.060 & .039 \\
Session 2-3 & -1.089 & .276 \\
\hline
\end{tabular}




\subsection{Socialization}

In the controlled laboratory experiments, the amount of social initiations from the children with ASD increased through sessions (table 6), and the amount of responses by ASD children also increased significantly from the first to the third session (ANOVA: $\mathrm{F}(2,9)=8.049, \mathrm{p}<.05$ ) (table 7). Responses were only considered if they answered a question from another interlocutor using appropriate timing and content. Finally, the total amount of social actions, which was a compound score of initiations, requests, responses and shared actions, significantly increased through the course of the laboratory sessions (table 8).

Table 6: Number of Social Initiations

\begin{tabular}{ccc}
\hline Source & $\mathrm{Z}$ & Sig. \\
\hline Session 1-1 & -1.569 & .117 \\
Session 1-3 & -2.810 & .005 \\
Session 2-3 & -1.899 & .058 \\
\hline
\end{tabular}

Table 7: Number of Responses by Children with ASD

\begin{tabular}{cccc}
\hline Source & $\mathrm{N}$ & $\mathrm{M}$ & $\mathrm{SD}$ \\
\hline Session 1 & 10 & 1.9 & .504 \\
Session 2 & 10 & 3.9 & .674 \\
Session 3 & 10 & 5.8 & 1.041 \\
\hline
\end{tabular}

Table 8: Total Amount of Social Acts

\begin{tabular}{ccc}
\hline Source & $\mathrm{Z}$ & Sig. \\
\hline Session 1-1 & -1.843 & .065 \\
Session 1-3 & -2.807 & .005 \\
Session 2-3 & -2.040 & .041 \\
\hline
\end{tabular}

In addition, video coding revealed that an average of 80.4 per cent of social activity during the laboratory and school setting trials was directly related to game events. This means that a majority of the conversation maintained during the game was directly inspired by or related to events occurring in the game. As the game was designed to include interesting and surprising elements, we see that 
the game served as a successful catalyst for sparking socialization opportunities during play.

The children also showed a tendency towards positive perception of the game as a basis for forming social relationships. In post-session questionnaires from the inclusive elementary school trials, 80 per cent of the children responded that it was easier to get their partner to play as time went on compared to other activities, and 67.5 per cent of children said they believe they would have talked less with their partner in a playground than in the virtual environment.

In addition to creating a comfortable zone for children with ASD to practice social behaviors, we also aimed to provide an opportunity for typically developed children to see that children with ASD could be credible play partners. After playing in the virtual environment, 65 per cent of TD children in the inclusive school indicated that they would like to get to know their partner better after playing together in Lands of Fog.

\subsection{Collaboration}

In the laboratory sessions, we saw that the number of manipulated virtual elements increased through sessions (ANOVA: $\mathrm{F}(2,9)=22.9, \mathrm{p}<.05$ ) (table 9). As these virtual elements could only be manipulated when both partners were working together, we can conclude that the partners were understanding and practicing the benefits of collaborating in the game. We also observed that the mean distance between children decreased significantly through the playing time (T-test: $\mathrm{t}(33)=2.119, \mathrm{p}<.05)$ (table 10$)$, in both the laboratory experiments and the integrated school experiments. Therefore, as the children were growing more comfortable with their partner in the virtual environment, they were also choosing to play together and share the experience as opposed to playing alone.

Table 9: Number of Virtual Elements Manipulated

\begin{tabular}{cccc}
\hline Source & $\mathrm{N}$ & $\mathrm{M}$ & $\mathrm{SD}$ \\
\hline Session 1 & 10 & 4.5 & 4.2 \\
Session 2 & 10 & 16.1 & 9.2 \\
Session 3 & 10 & 23.5 & 6.6 \\
\hline
\end{tabular}


Table 10: Mean Distance between Children (cms)

\begin{tabular}{cccc}
\hline Source & N & M & SD \\
\hline Beginning of Session & 34 & 204.40 & 55.36 \\
End of Session & 34 & 182.28 & 57.24 \\
\hline
\end{tabular}

\subsection{Perception}

When asked about their perception of the game, 95 per cent of the children at the elementary school responded positively to the idea of playing again. We asked the children to compare the experience of playing in the game to other school activities. From this, 95 per cent of children with ASD said they had enjoyed playing with their partner more in Lands of Fog than they would have in physical education, and 70 per cent of children reported that they had enjoyed working with their partner more in the game than they would have in a science practical. We also found that children with ASD enjoyed significantly higher working with the partner than typically developed children in the game than in Physical Education (Wilcoxon: $\mathrm{Z}=-2.44, \mathrm{p}<.05$ ), which could be an indicator that the game is less daunting compared to other playful activities.

\section{Discussion}

\subsection{Potentialities for therapy}

We can see in the results an increase of purposeful activity through sessions in the laboratory controlled trials reflecting that users' activity became more focused as they learned how to interact with the system. These results seem to indicate that the addition of a simple initial mechanic, such as hunting fireflies, was a successful design strategy to help children get acquainted with the system. Furthermore, the subtle introduction of richer mechanics through play seems to have helped children to flow from the more individual and simple mechanics, to the collaborative ones such as merging or manipulating virtual elements. This seems to be in consonance with what Davis et al. proposed [35]. 
In the laboratory trials, we wanted to have a controlled setting which would allow for assessment of the system's goals of user motivation, socialization, and collaboration. The fact that the children showed improvements in these areas through the course of multiple sessions indicates the system's potential as a tool for intervention or therapy. Social therapy approaches for children with ASD require a large degree of dedication from trained therapists. Therefore, providing controlled systems which are programmed to adapt to changes in children's behavior could assist therapists by providing consistent and immediate support, thus lowering the therapists' individual workload.

This study is unique in its approach of fostering social initiation as opposed to specific social skills. Nonetheless, the positive findings with Lands of Fog as a system to scaffold behavior seem to be in consonance with other projects using virtual environments to teach social behaviors, as presented in the Background section [27, 23, 28,.

The data analysis showed a significant increase in the number of environmental elements manipulated by the players. As environmental elements were only able to be activated in collaboration with the other player, the players had to communicate amongst themselves and decide on a unified plan of action. Another variable that could have demonstrated positive social interaction was the number of times that the players merged their creatures which increased in the laboratory trials from 5.2 in the first session to 6.7 in the third session of the laboratory trials. This interesting game mechanic was also a good motivator for children to work together for a common goal, discover all the creatures.

The fact that environmental element manipulations and creature mergings were occurring consistently throughout the sessions shows a presence of collaboration behaviors, and the significant increase in the occurrence of these indicates the games potential to foster positive social interaction attitudes.

\subsection{Possibilities for school implementation}

After testing the functionality of the system in a controlled laboratory environment, we assessed the deployment of the system in an elementary school. 
One of our goals for these sessions was to determine the reception by the school community after one week of experimental trials.

At the end of the week, faculty members and any children who had participated were invited to an informal information session, where they gave their opinions and interpretations of the game. At this point, we saw that there was a wide range of narratives that the children had formed as a result of the open nature of the game. During the information session, we saw that the children were eager to share their experiences with one another, and the school faculty commented on the rich mixture of children who were interacting outside of their normal social groups as a result of a new shared experience with Lands of Fog.

During the trials, we also saw that the game served as a way to mediate socialization between individuals who had not met before or were just school acquaintances. The video coding results show us that the game served as a solid helper since a high rate of social bids were directly related to the game events and elements. We saw that not only did children who met for the first time enjoy the experience of playing together, but also the school students who knew each other but had no friendship had a good time too. Moreover, we saw that the less they knew their partner prior to playing, the more they saw the game as a useful scenario to facilitate conversation when compared to playground time (figure 5), with a Pearson correlation $=0.29, \mathrm{p}=.073$ (2-sided). Despite the low Pearson correlation we see a positive tendency which needs to be further explored. As fragmentation of social relationships occurs at a higher rate among children with ASD, installations such as Lands of Fog could be useful additions to school settings to unite students through an enjoyable common experience. These kinds of settings could be useful to provide support during unstructured social scenarios as Anderson proposed [7].

\subsection{Limitations}

Our results show the efficacy of Lands of Fog as a system to foster engagement, socialization and collaboration. Both studies were focused on assessing whether the system we developed was successful for these objectives. In future 


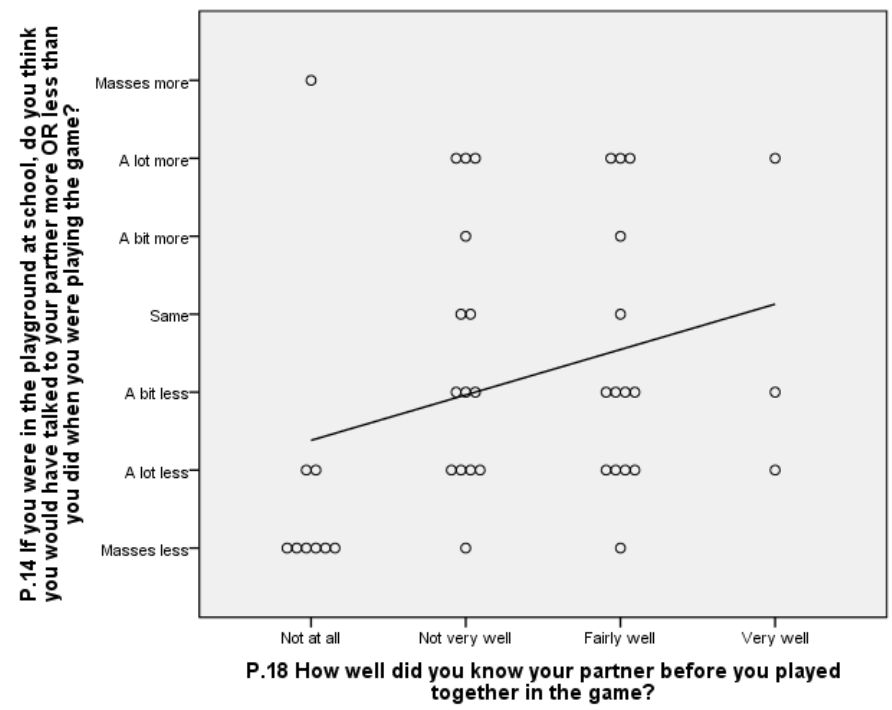

Figure 5: Scatter plot correlating answers to how much children knew their partner to if they thought they would have talked more to their partner in the playground than in the game.

experiments the system should be assessed on a long-term defined program in a classroom or group therapy setting to assess its potential as an intervention tool. In addition, future research should explore the different approaches to inclusion of children with ASD in education, and how it could be taken into account for the design process of such systems.

\section{Conclusions}

In this article we have presented the positive results from two studies to experimentally assess the full-body interaction virtual environment Lands of Fog. Results show that Lands of Fog was successful on motivating users to engage with the system, while also fostering social and collaborative behaviors between players. Moreover, parent, professional and user feedback shows that the game was well received.

We believe that Lands of Fog demonstrates the potential of technology to design systems which can be deployed in special education centers and inclusive schools as intervention tools, and also as aids for social inclusion for children 
with ASD.

While developing systems for individuals with special needs, we think it is important to take them into account as design informants and work closely with professionals for developing a successful installation.

According to post-session questionnaires, children with ASD at the inclusive elementary school found it easier to form social bonds (the basis of social relationships) when playing in Lands of Fog, as compared to typical school settings like PE or science class. Typically developed children also enjoyed the experience of playing with Lands of Fog, and furthermore the majority viewed their partner with ASD as a valuable colleague and expressed their desire to get to know their partner better after playing.

This project represents the first time that such an ICT approach has been used, given that it uses full-body interaction applied for a multi-user experience to foster social initiation behaviors in ASD children. Taking into account the characteristics of the system where users are present and able to socialize in a colocated environment, we believe results prove the benefits of such an approach and the potential of similar technologies based on embodied cognition theories. This opens a number of previously uncertain doors for new future research and exploration.

Finally, the timeline of trials at the inclusive school allowed each child to play in the game for a single session. Given the positive results across multiple sessions from the laboratory trials, we believe that the permanent presence of this type of installation in an inclusive school environment would be useful in strengthening the social relationships between members of the school community. Nonetheless, we believe that a longitudinal assessment of the system in an inclusive school setting must be conducted to further assess the potentials of such tools. It could also be interesting to assess in the future the potential impacts of such a novel tool in a Special Education center or Inclusive School, given that it could reshape how children perceive playtime activities.

Moreover, although it was not statistically significant, we observed some playing differences between male and female participants in London, as females 
tended to show less engagement at the beginning of play. This could be related to the fact that the Participatory Design sessions consisted of only male participants. Further research must focus on the gender distribution during PD and how it affects acceptance of the final design by both genders.

\section{Acknowledgements}

The project was funded by RecerCaixa 2013. We would like to thank Hospital Sant Joan de Déu for their support. To Laia Margarit who assisted in the Barcelona trials. We would also like to thank The Elmgreen School in London for offering their school as an experimental setting. Finally, thank you to all the children and families who made our study possible.

\section{References}

[1] A. P. Association, Diagnostic and statistical manual of mental disorders (5th ed.), 5th Edition, Washington, DC, 2013. doi:10.1176/appi.books. 9780890425596.744053

[2] P. A. Filipek, P. J. Accardo, S. Ashwal, G. T. Baranek, E. H. Cook, G. Dawson, B. Gordon, J. S. Gravel, C. P. Johnson, R. J. Kallen, S. E. Levy, N. J. Minshew, S. Ozonoff, B. M. Prizant, I. Rapin, S. J. Rogers, W. L. Stone, S. W. Teplin, R. F. Tuchman, F. R. Volkmar, Practice parameter: Screening and diagnosis of autism: Report of the Quality Standards Subcommittee of the American Academy of Neurology and the Child Neurology Society, Neurology 55 (4) (2000) 468-479.

URL http://www . neurology .org/content/55/4/468.full

[3] C. Lord, M. Rutter, P. C. DiLavore, S. Risi, Autism Diagnostic Observation Schedule, Los Angeles, 2001.

URL

http://www.wpspublish.com/store/p/2647/ autism-diagnostic-observation-schedule-ados 
[4] J. L. Sanders, Qualitative or quantitative differences between Asperger's disorder and autism? Historical considerations., Journal of autism and developmental disorders 39 (11) (2009) 1560-7.

URL http://www.ncbi.nlm.nih.gov/pubmed/19548078

[5] O. Grynszpan, J.-C. Martin, J. Nadel, Multimedia interfaces for users with high functioning autism: An empirical investigation, International Journal of Human-Computer Studies 66 (8) (2008) 628-639. doi:10.1016/j.ijhcs.2008.04.001.

URL http://www.sciencedirect.com/science/article/pii/ S1071581908000402

[6] N. Bauminger-Zviely, E. Karin, Y. Kimhi, G. Agam-Ben-Artzi, Spontaneous peer conversation in preschoolers with high-functioning autism spectrum disorder versus typical development, Journal of Child Psychology and Psychiatry 55 (4) (2014) 363-373. doi:10.1111/jcpp.12158

URL http://www.ncbi.nlm.nih.gov/pubmed/24304222

[7] A. Anderson, J. Locke, M. Kretzmann, C. Kasari, AIR-B Network, Social network analysis of children with autism spectrum disorder: Predictors of fragmentation and connectivity in elementary school classrooms, Autismdoi:10.1177/1362361315603568.

[8] V. Bolic Baric, K. Hellberg, A. Kjellberg, H. Hemmingsson, Support for learning goes beyond academic support: Voices of students with Asperger's disorder and attention deficit hyperactivity disorder., Autism : the international journal of research and practice 20 (2) (2016) 183-95.

URL http://aut.sagepub.com/content/early/2015/04/23/ 1362361315574582.abstract

[9] K. Bottema-Beutel, T. S. Mullins, M. N. Harvey, J. R. Gustafson, E. W. Carter, Avoiding the "brick wall of awkward": Perspectives of youth with autism spectrum disorder on social-focused intervention practices. Autism : the international journal of research and practice (2015) 
1362361315574888 doi:10.1177/1362361315574888.

URL http://aut.sagepub.com/content/early/2015/04/16/ 1362361315574888.abstract

[10] J. Brown, D. Murray, Strategies For Enhancing Play Skills For Children With Autism Spectrum Disorder, Education and Training in Mental Retardation and Developmental Disabilities 36 (3) (2001) 312-317.

[11] M. Moore, S. Calvert, Brief Report: Vocabulary Acquisition for Children with Autism: Teacher or Computer Instruction, Journal of Autism and Developmental Disorders 30 (4) 359-362. doi:10.1023/A:1005535602064 URL http://link.springer.com/article/10.1023/A\% 3A1005535602064

[12] A. Alcorn, H. Pain, G. Rajendran, T. Smith, O. Lemon, K. PorayskaPomsta, M. E. Foster, K. Avramides, C. Frauenberger, S. Bernardini, Artificial Intelligence in Education, Vol. 6738 of Lecture Notes in Computer Science, Springer Berlin Heidelberg, Berlin, Heidelberg, 2011. doi : $10.1007 / 978-3-642-21869-9$.

URL https://pure.strath.ac.uk/portal/en/publications/ social-communication-between-virtual-characters-and-children-with-autism (035586b0-d868/export.html

[13] L. C. Mechling, D. L. Gast, B. A. Cronin, The Effects of Presenting High-Preference Items, Paired With Choice, Via Computer-Based Video Programming on Task Completion of Students With Autism, Focus on Autism and Other Developmental Disabilities 21 (1) (2006) 7-13. doi: $10.1177 / 10883576060210010201$.

URL http://foa.sagepub.com/content/21/1/7.abstract

[14] G. R. Hayes, S. Hirano, G. Marcu, M. Monibi, D. H. Nguyen, M. Yeganyan, Interactive visual supports for children with autism, Personal and Ubiquitous Computing 14 (7) (2010) 663-680. doi:10.1007/ 
s00779-010-0294-8.

URL http://link.springer .com/10.1007/s00779-010-0294-8

[15] O. Golan, S. Baron-Cohen, Systemizing empathy: Teaching adults with Asperger syndrome or high-functioning autism to recognize complex emotions using interactive multimedia, Development and Psychopathology 18 (2006) 591 - 617. doi:10.1017/S0954579406060305.

URL http://docs.autismresearchcentre.com/papers/2006_Golan_ SystemizingEmpathy.pdf

[16] M. Tentori, G. R. Hayes, Designing for interaction immediacy to enhance social skills of children with autism, in: Proceedings of the 12th ACM international conference on Ubiquitous computing - Ubicomp '10, ACM Press, New York, New York, USA, 2010, p. 51. doi:10.1145/1864349. 1864359

URL http://dl .acm.org/citation.cfm?id=1864349.1864359

[17] D. M. Casenhiser, S. G. Shanker, J. Stieben, Learning through interaction in children with autism: preliminary data from asocial-communicationbased intervention., Autism : the international journal of research and practice 17 (2) (2013) 220-41.

URL http://aut.sagepub.com/content/early/2011/09/20/ 1362361311422052

[18] R. J. Landa, K. C. Holman, A. H. O'Neill, E. A. Stuart, Intervention targeting development of socially synchronous engagement in toddlers with autism spectrum disorder: a randomized controlled trial., Journal of child psychology and psychiatry, and allied disciplines 52 (1) (2011) 13-21. doi:10.1111/j.1469-7610.2010.02288.x.

URL http://www.pubmedcentral.nih.gov/articlerender.fcgi? artid=3059234\&tool=pmcentrez\&rendertype=abstract

[19] K. Pajareya, K. Nopmaneejumruslers, A pilot randomized controlled trial of DIR/Floortime parent training intervention for pre-school children with 
autistic spectrum disorders., Autism : the international journal of research and practice 15 (5) (2011) 563-77.

URL http://www.ncbi.nlm.nih.gov/pubmed/21690083

[20] M. Wilson, Six views of embodied cognition, Psychonomic Bulletin \& Review 9 (4) (2002) 625-36. doi:10.3758/BF03196322.

URL http://link.springer.com/article/10.3758\%2FBF03196322

[21] N. Bianchi-Berthouze, W. W. Kim, D. Patel, Affective Computing and Intelligent Interaction, Vol. 4738 of Lecture Notes in Computer Science, Springer Berlin Heidelberg, Berlin, Heidelberg, 2007.

URL http://dl .acm.org/citation. cfm?id=1422168.1422180

[22] L. Millen, R. Edlin-White, S. Cobb, The development of educational collaborative virtual environments for children with autism, 5th Cambridge Workshop on Universal Access and Assistive Technology.

[23] Y. Cheng, J. Ye, Exploring the social competence of students with autism spectrum conditions in a collaborative virtual learning environment The pilot study, Computers \& Education 54 (4) (2010) 1068-1077. doi:10. $1016 / j . c o m p e d u .2009 .10 .011$.

URL http: //dl .acm .org/citation. cfm?id=1749620.1749753

[24] S. Parsons, S. Cobb, State-of-the-art of virtual reality technologies for children on the autism spectrum, European Journal of Special Needs Education 26 (3) (2011) 355-366. doi:10.1080/08856257.2011.593831.

URL http://www .tandfonline.com/doi/abs/10.1080/08856257.2011. 593831

[25] P. Mitchell, S. Parsons, A. Leonard, Using virtual environments for teaching social understanding to 6 adolescents with autistic spectrum disorders. Journal of autism and developmental disorders 37 (3) (2007) 589-600.

URL http://www.ncbi.nlm.nih.gov/pubmed/16900403 
[26] N. Pares, P. Masri, G. van Wolferen, C. Creed, Achieving dialogue with children with severe autism in an adaptive multisensory interaction: the "MEDIATE" project., IEEE transactions on visualization and computer graphics 11 (6) 734-43.

URL http://www.ncbi.nlm.nih.gov/pubmed/16270865

[27] X. Casas, G. Herrera, I. Coma, M. Fernandez, A Kinect-based Augmented Reality System for Individuals with Autism Spectrum Disorders, in: Proceedings of the International Conference on Computer Graphics Theory and Applications, SciTePress - Science and and Technology Publications, 2012, pp. 440-446. doi:10.5220/0003844204400446.

URL http://www.scitepress.org/DigitalLibrary/ PublicationsDetail. asp $x$ ? ID $=5$ REEawmgpko $=\& t=1$

[28] K. Porayska-Pomsta, C. Frauenberger, H. Pain, G. Rajendran, T. Smith, R. Menzies, M. E. Foster, A. Alcorn, S. Wass, S. Bernadini, K. Avramides, W. Keay-Bright, J. Chen, A. Waller, K. Guldberg, J. Good, O. Lemon, Developing technology for autism: an interdisciplinary approach, Personal and Ubiquitous Computing 16 (2) (2011) 117-127. doi:10.1007/ s00779-011-0384-2.

URL http://link.springer.com/10.1007/s00779-011-0384-2

[29] C. Frauenberger, J. Good, A. Alcorn, H. Pain, Supporting the design contributions of children with autism spectrum conditions, in: Proceedings of the 11th International Conference on Interaction Design and Children, 2012, pp. 134-143. doi:10.1145/2307096.2307112.

[30] P. Ehn, Work-Oriented Design of Computer Artifacts. URL http://dl.acm.org/citation.cfm?id=1102017

[31] L. Malinverni, J. Mora-Guiard, N. Pares, Towards methods for evaluating and communicating participatory design: A multimodal approach, International Journal of Human-Computer Studies (2016) Manuscript submitted for publication.doi:10.1016/j.ijhcs.2016.03.004. 
URL

http://linkinghub.elsevier.com/retrieve/pii/

S1071581916000367

[32] J. Mora-Guiard, C. Crowell, N. Pares, P. Heaton, Lands of Fog: helping children with Autism in social interaction through a full-body interactive experience, in: ACM SIGCHI Interaction Design and Children 2016, 2016, p. manuscript submitted for publication. doi:10.1145/2930674.2930695

[33] P. Hoberman, N. Pares, R. Pares, El ball del fanalet or lightpools, in: Proceedings of International Conference on Virtual Systems and Multimedia, Dundee, UK, 1999, pp. 270-276.

[34] P. Dalsgaard, C. Dindler, Between theory and practice, in: Proceedings of the 32nd annual ACM conference on Human factors in computing systems - CHI '14, ACM Press, New York, New York, USA, 2014, pp. 1635-1644. doi:10.1145/2556288.2557342.

URL http://dl .acm.org/citation. cfm?id=2611528.2557342

[35] M. Davis, K. Dautenhahn, S. D. Powell, C. L. Nehaniv, Guidelines for researchers and practitioners designing software and software trials for children with autism, Journal of Assistive Technologies 4 (1) (2010) 38-48. doi:10.5042/jat.2010.0043

[36] D. Wechsler, Wechsler Intelligence Scale for Children., Psychological Corporation, San Antonio, 1949. 